\title{
Special Issue Editorial
}

\section{RobertVernon}

W elcome to our special edition focusing on assessment. We have the pleasure of presenting eight articles that address assessment in social work education from a variety of perspectives. These contributions were chosen in keeping with the philosophy of this journal: The examination of issues and ideas that will influence how our profession will address the countless assessment questions we continually discover.

Assessment is interwoven throughout the fabric of social work education. We continually take stock of what we are doing and how well we are accomplishing our intended goals. It permeates our academic lives whether we notice it or not. Assessment presents itself when we emerge from class. Are we smiling or frowning because of what occurred? Assessment happens when we select textbooks. Are we happy with our choices or do we have the urge to write our own? Assessment is salient again when we craft syllabi. We can only cram so much into 15 weeks-something has to go-yet, we know from professional wisdom that we easily could use more time. It comes into play when the faculty meets to take stock of what the curriculum is accomplishing. Is graduation joyful because we are confident in what we have created? Or do we cross our fingers from reservations and misgivings? And, assessment presents itself when we engage in the self-study process for accreditation. Most of us feel torn between pride and anxiety when that site visit team arrives to assess our work.

As a person who has brought two social work programs through the complete precandidacy-initial accreditation process, served on numerous site visits, and is currently serving on the Council on Social Work Education (CSWE) Commission on Accreditation, I can attest that the complexities and challenges of assessment are enormous. There is no single path. There is no unique way to create a sound social work curriculum. There is no one way to deliver it. The Educational Policy and Accreditation Standards (EPAS) from CSWE (2003) provide benchmarks. These standards establish content and assessment specifications, but how we choose to incorporate them is most challenging. EPAS's Accreditation Standard 8.0 is especially salient: We must have an assessment plan and procedures in place for evaluating every program objective within the curriculum, including specific measures, procedures, and methods. Standard 8.1 is just as crucial: We must implement the plan and continually use the results to affirm and improve the program. Perhaps assessment is best understood as an art, the willful choice to pursue evaluative knowledge from countless sources of potential information towards fulfilling this obligation. We select some approaches and sources but neglect others. The eight articles presented in this edition provide ideas about how this process may be undertaken and how these choices may be made.

One of my more interesting tasks has been choosing the presentation order for this issue. While some readers will only want to read occasional contributions, others 
may want to enjoy this issue from cover to cover. This has made sense-making out of the diversity in the contributions a challenge. The following underlying order has been crafted:

\section{The Big Picture...}

The first contribution by Dr. Charles Zastrow and Dr. Tim Reutebuch provides insight into the Gestalt of program design. The authors map out a fairly comprehensive vision of how to approach assessment within the program design and accreditation process. Just as the Baer-Federico report (1978) guided us in the '80s, this article illustrates a model approach to developing an accreditable program and specifically delineates where assessment fits in. Using their own school as a case, the authors provide detailed information-including instruments-that readers who are in the beginning stages of creating a social work program may find invaluable. For the more established programs, the article provides an excellent perspective on what one program accomplishes through assessment and how colleagues go about this process.

\section{Gatekeeping...}

How many of us have had to "council out" inappropriate students who discover well into their studies that they should have focused their pursuits elsewhere? The second contribution from Larry Reynolds looks at quality control in the admissions process, hopefully towards preventing this problem. Again, presenting instrumentation, Professor Reynolds examines a much-neglected area: The course work students take prior to acceptance into the program. We have a gap in our literature: How do we craft a methodology that helps us assess potential students before we let them in? This article provides steps toward using preparatory coursework as a benchmark for potential student success. It illustrates how we may begin to establish benchmarks in this important area.

Even when we have established criteria and benchmarks for admissions, do these really work? The third article by Professors Thomas, McClearey, and Henry asks this difficult question. They provide an interesting history and overview of this area. They then examine the effectiveness of admission criteria on graduate student performance in the classroom and field. Just how effectively does the Graduate Record Exam serve as a predictor for classroom performance? What about the student grade point averages? And those gl owing reference letters? Quality control over whom we admit into our programs has an eventual effect on the lives our graduates touch. Both articles in this section provide insights into the gatekeeping process.

\section{Classroom Assessment..}

Once admitted, Dr. Paul Adams shows a way to listen to the heartbeat of the classroom. All of us strive for dynamic, learner-friendly classrooms that focus on critical thinking. Our day-to-day, class-by-class events shape this. How do we assess these efforts? Professor Adams describes fine-grained assessment activities: Classroom assessment techniques, such as polling students about the "muddiest point" that they did not understand. This approach provides ongoing assessment feedback. Combined with other approaches from the literature, this case presentation on micro-assessment promotes the art of discerning just what worked well and what did not. 
Just how confident can we be in our assessment measures? Drs. Cathy Pike, Robert Bennett, and Valerie Chang's efforts in instrument validation providea methodological example. They compare two instruments that assess how well students interview-a core skill for social work practice. In their comparative examination of a classical instrument and a new one, the authors demonstrate how construct validity, reliability, and a clear factor structure can help establish confidence in assessment efforts and measures.

\section{Online Course Assessment..}

Our profession has only recently come to grips with web-based teaching, where the instructor may never even physically meet the students. How can one assess these online courses? Articles six and seven take this up through two evaluative reports. Dr. Zvi Gellis takes data from a clinical research methods course and explores various facets of online instruction from the learner's perspective. This qualitative study illustrates one approach to assessing the dimensions of online learning. A collaborative learning and teaching framework is presented for those social work educators interested in implementing web-based courses and assessing how well they accomplish their objectives.

Drs. Philip Ouellette and Valerie Chang take web-based learning a step further in their preliminary assessment of how well a traditionally taught classroom-based practice course on interviewing skills compares with a completely web-based course, where the students never meet each other or the instructor face to face. This is a "third rail" issue: Can you really teach practice in a total web environment? Students' background characteristics and their perceptions of their learning experience and skill acquisition are compared and reported as preliminary findings. The initial results are provocative and we look forward to learning more from their findings.

\section{Portfolio as an Assessment Approach...}

Dr. Mona Schatz looks at the larger summative perspective: Assessment through portfolios. In her study of a graduate-level portfolio approach, she investigates whether this technique promotes critical thinking, class and field learning integration, reflective thinking, professional socialization, and practice competence. She also investigates efficiencies: Does an adequate portfolio really necessitate endless hours of work on the part of the student?

\section{Further Investigation}

Finally, as editor, I am most grateful to my colleague Mary Stanley, Associate Dean for the University Library and Liaison to the School of Social Work. Together, we have amassed a large bibliography on social work assessment for the reader's continued research. We cast a fairly wide net and, while we have probably missed a few favorite articles, we have attempted to provide a sound beginning research bibliography for social work education assessment.

As editor for this edition, I have had thetask of soliciting contributions, overseeing the jury process, and editing the chosen contributions for publication. I am deeply indebted to those colleagues who chose to submit their work. I regret that we are not able to share them all. I am also indebted to the colleagues who painstakingly reviewed the submissions. Many reviewers clearly spent hours carefully examining 
and assessing the contributors' thoughts and work. Finally, I deeply appreciate the support I have enjoyed from my associates on the journal's editorial board.

\section{References}

Council on Social Work Education. (2003). Handbook of Accreditation Standards and Procedures, $5^{\text {th }}$ edition, Alexandria, VA: Author.

Baer, B., \& Federico, R. (1978). Educating the baccalaureate social worker. Cambridge, MA: Ballinger Publishing Company. 